\title{
EDUCACIÓN
}

\section{Estrategias para el desarrollo de la inteligencia emocional en niños del nivel inicial de la Escuela Básica N 6935 Privada Subvencionada C.F.I. Sandra Rosalía. Año 2018}

Lidia Marisel Acuña Allende1, Mercedes Natividad Mancuello Gavilán

\section{Resumen}

Introducción: La inteligencia emocional es una habilidad necesaria para el buen Desenvolvimiento social de las personas ya que le ha proporcionado la facilidad para conocer y reconocer sus estados emocionales, desde que surgió ha impactado en la vida de millones de personas en distintas etapas sea en lo formativo o en lo profesional.

Objetivo: Analizar las estrategias que utilizan los docentes para el desarrollo de la inteligencia emocional en niños del nivel inicial de la Escuela Básica Nº 6935 Privada Subvencionada C.F.I. Sandra Rosalía.

Material y Método: Diseño no experimental de enfoque cualitativo y descriptivo Resultados de categoría de análisis

Técnicas: Como resultado de los instrumentos se pudo constatar que los docentes utilizaron técnicas como: técnica del semáforo, el bosque encantado, carrera de hojas, abrazos musicales y la gran tortuga; los cuales se consideran que ayudan a los niños a controlar sus emociones, ser consciente de su comportamiento, evitar situaciones frustrantes a automotivarse a valorarse como miembro de un grupo y enriquecer sus habilidades sociales.

Actividades: Durante los momentos didácticos, tales como juegos, canciones y el uso de imágenes coloridas los cuales promueven el adecuado desarrollo de la inteligencia emocional en el nivel inicial.

Momentos didácticos: Se han implementado estrategias para el desarrollo de la inteligencia emocional durante todos los momentos didácticos, promoviendo el interés de los niños, dado que les permite el aprendizaje significativo durante el inicio, desarrollo y el cierre de las actividades.

Conclusiones: La mayoría de los autores definen la inteligencia emocional como la habilidad para manejar las emociones personales, entender la de otros; a fin de que a través de un adecuado manejo se pueda llegar a la empatía general, base de una sociedad armónica, funcional y en crecimiento.

1. UNIBE. Facultad de Humanidades. Psicopedagogía.

Tesis presentada para la obtención de la licenciatura.

E-mail: kaware79@gmail.com

DOI: $10.26885 /$ rcei.foro.2018.76 
Los mismos coinciden que para llegar a esta empatía, es necesaria la inclusión en la malla curricular con el objetivo de fijar las bases de una conducta emocional controlada y de esa manera se pueda crecer y seguir con la evolución natural. Con este estudio se pudo identificar técnicas las cuales tienen como objetivo que los niños se automotiven, conozcan las situaciones de las demás y se controlen ante los momentos difíciles para ellos.

Se puede considerar que las estrategias aplicadas por los docentes para el desarrollo de la inteligencia emocional de los niños son adecuadas ya que las mismas aplican el autocontrol, la autoconciencia, automotivación, empatía y habilidades sociales dentro del salón de clase, cuando se reaccionan con los demás y su entorno.

Palabras clave: inteligencia emocional, técnicas, actividades, recursos.

\section{REFERENCIAS}

Bar-On, D. R. (1980). EQ-i, Bar-On Emotional Quotient Inventory. (Technical manual). Toronto, Canada: Multi-Health Systems.

Goleman, D. (1995). Libro original: Emotional Intelligence. Editorial Kairós.

Salovey. P. \& Mayer, J. D. (1990). Emotional Inteligence: Imagination, Cognition and Personatity. New York: Basic Books.

Sampieri, R.H. (2010). Metodología de la investigación. Editorial Mc Graw Hill. 